\title{
Arte e Identidade: Estratégias do jogo social
}

Patrícia Reinheimer PPGAS-MN
O objetivo deste artigo $^{1}$ é investigar a idéia de jogos sociais a partir da forma como estes foram observados na etnografia do projeto de intervenção Arte em Ação Ambiental $-\mathrm{A}_{3^{\prime}}$ da qual resultou a dissertação de mestrado em Antropologia Social acima indicada. Sendo a idéia de jogo o eixo central através do qual o projeto $A_{3}$ trabalhava, usou-se essa noção como uma categoria nativa a partir da qual pensar o processo de civilização dos costumes e construção de identidades idealizado e parcialmente empreendido pelo $A_{3}$. A experimentação artística e a relação do grupo de jovens de uma comunidade próxima ao Museu de Arte Contemporânea de Niterói com alguns artistas, objetos de arte e o meio artístico disponibilizada para eles através daquela instituição foi a forma como esse processo foi colocado em prática.

Aproveitou-se também para discutir a noção de jogo aplicada às relações entre os diversos atores e os valores e regras sociais que se apresentaram nos espaços e grupos sociais que conformaram o campo da pesquisa. A idéia de jogo então é utilizada como uma metáfora para desvelar, a partir da noção de regras negociáveis e estratégias, a reorganização dos significados acarretada pela introdução de novas condições, sejam atores sociais, valores ou instituições na pequena política do cotidiano (Bailey 1971).

O tema da pesquisa de mestrado surgiu como desdobramento de uma investigação sobre projetos educativos elaborados no interior dos museus de arte do Rio de Janeiro. A proposta inicial consistia em observar a relação entre as artes plásticas, no âmbito dessas instituições, e a educação artística formal e não-formal ${ }^{2}$, parecendo serem os museus um campo privilegiado para se perceber os conflitos e as ambigüidades que surgem nessas relações.

Sendo o museu uma das instituições através das quais o Estado atualiza a noção de um compromisso com a educação de seus cidadãos, existe uma idéia de missão civilizatória (Duncan 1995) implícita nessas instituições cuja ideologia remete à origem de sua forma moderna, no século XVIII, como instituição cunhada 
para corroborar e disseminar certos ideais. Dentro dessas instituições, as divisões e departamentos de educação cumprem, em grande medida, o papel de mediadores entre o museu a que pertencem e os conceitos e noções que fundamentam sua práxis e o público; ao mesmo tempo, podem se constituir como importantes mediadores entre as escolas e as próprias instituições ao se apresentarem como espaço de exploração, visualização e questionamento dos conceitos e convenções transmitidos pelos professores de arte da educação formal.

Dependendo a viabilização de uma pesquisa, em grande parte, das relações que o pesquisador mantém no interior da estrutura de relações que conformam o campo a ser pesquisado, o Museu de Arte Contemporânea de Niterói - MAC impunha-se como um campo de observação empírica peculiar. Além de ter trabalhado nessa instituição como estagiária da divisão de educação, também havia ministrado uma oficina informal ${ }^{3}$ de introdução à programação visual no projeto de intervenção Arte em Ação Ambiental. Essa condição tornava o papel de observadora uma identidade a ser construída a partir da reformulação das relações de participação intensa com o museu e as atividades educativas ali desenvolvidas.

O projeto $A_{3}$ foi elaborado e implementado pela divisão de educação do MAC, em colaboração com um grupo de profissionais externos ao quadro de funcionários da instituição, tendo como eixo central de sua proposta a noção de construção de identidade. A questão da identidade aparecia como uma linguagem na luta política, uma moeda de troca na justificativa desse, assim como de outros projetos de intervenção, que não teriam como finalidade oferecer uma formação profissional em artes. As artes seriam os meios através dos quais o projeto propunha contribuir na construção das identidades sociais dos jovens ${ }^{4}$ participantes sem, entretanto, propor a formação de artistas plásticos. A partir daí vislumbrou-se uma possibilidade de desvendar alguns dos processos sociais nos quais as artes plásticas se inscreveriam dentro de estratégias de alocação e distribuição de valor no processo de construção de identidades.

\section{O PROJETO ARTE EM AÇÃO AMBIENTAL}

O projeto Arte em Ação Ambiental começou a ser implementado em 1998, como parte da estratégia da Divisão de Educação do Museu de Arte Contemporânea de Niterói de expandir sua atuação para além do público freqüentador da instituição, baseada em um conceito amplo como o de "cidadania cultural", o que significava para os elaboradores do projeto atuar "junto às comunidades marginalizadas dos processos educativos e da produção artística" ${ }^{5}$. A noção de cidadania estaria referida aos processos de responsabilização individual, racionalização e disciplinarização a partir de normas de conduta e comportamento específicas que definiriam cidadania como um termo de conotações cívicas e de participação em um mercado de trabalho.

Esse objetivo deveria ser alcançado através da construção de espaços dentro da comunidade onde seriam oferecidas oficinas artesanais diversas, algumas visando a produção de artigos que pudessem ser comercializados. O projeto contava com quatro oficinas principais: oficina de reaproveitamento/reciclagem de papel; oficina de sensibilização, percepção e diagnóstico ambiental - que trabalhava com teatro; oficina de jogos neoconcretos 
- cujo foco central eram artes plásticas; e oficina de reciclagem de material orgânico (produção de adubo orgânico, cultivo de plantas).

O principal eixo do projeto e o mais diretamente relacionado ao Museu era a oficina de Jogos Neoconcretos ${ }^{6}$. A partir do trabalho de alguns artistas presentes na coleção do museu, diversos materiais - arame, sabão, papel etc. - foram utilizados para experimentação plástica, tendo a noção de jogo como orientadora do processo. A oficina constituiu-se de um longo processo de assimilação dos autores e obras do movimento neoconcreto, de sensibilização com relação aos elementos da linguagem plástica (cores, formas, texturas etc.), e de experimentação das possibilidades construtivas dos diversos materiais disponíveis para a construção dos jogos, o refinamento no acabamento das peças e a produção para a venda desses jogos na loja do museu ou por encomendas.

Assim, os processos de racionalização, individualização e disciplinarização, junto com a idéia de regras tratadas como uma brincadeira, seriam a base para a criação dos jogos e a interação com estes, constituindo a própria oficina um jogo de aprendizado de regras que ia muito além daquelas relacionadas às obras dos artistas em questão: funcionava como processo de produção/domesticação dos corpos e do olhar e de 'racionalização' dos comportamentos do grupo que participava do programa.

Os jogos trabalhados nessa oficina supunham dois níveis de regras: as regras intrínsecas à noção de jogo em questão - variação, movimento, repetição - e as regras definidas a partir das obras dos artistas específicos - Lygia Clark, Sérgio Camargo, Abraham Palatnik, Hélio Oiticica, Ivan Serpa, Aluísio Carvão e lone Saldanha. O produtor do jogo deveria identificar as regras que, teoricamente definidas anteriormente pelo artista, iriam contê-lo, disciplinálo na fabricação de seu artefato para, a partir daí, criar seu jogo. Os jogos produzidos na oficina assemelhavam-se às obras de arte neoconcretistas.

Entretanto, a noção de jogo também serve para pensar a relação entre os valores e projetos dos diversos agentes envolvidos direta ou indiretamente com o projeto $A_{3}$. Os jogos sociais envolvidos no processo de disciplinarização dos corpos e dos gostos possibilitam o uso dessa noção 'nativa' para examinar várias dimensões nas quais o processo social no interior do qual se engendrou o projeto pode ser compreendido como um jogo cujas regras eram constantemente negociadas pelos diversos atores sociais que, por sua vez, eram constrangidos pelo contexto histórico social.

\section{CIVILIZAÇÃO DOS COSTUMES: O JOGO ENTRE CONJUNTOS DE VALORES DIFERENTES}

O processo de construção da identidade, individual ou coletiva, não tem origem nem fim, é um processo ininterrupto de negociação de valores no qual as pessoas e os grupos se definem e redefinem uns em relação aos outros. A inscrição no corpo de processos físicos e mentais é parte dessa construção e as transformações do comportamento e da forma de vestir dos participantes do projeto Arte em Ação Ambiental chamaram atenção da pesquisadora durante o período observado ${ }^{7}$. Essas transformações estavam em grande medida referidas às expectativas dos grupos envolvidos na elaboração e implementação do projeto, mas não necessariamente encontravam eco nos valores compartilhados pelos jovens em seu ambiente de convívio social fora do MAC. 
Assim que o grupo começou a freqüentar o museu, seus costumes foram alvo de um estranhamento que gerou comentários reprovadores por parte, principalmente, dos altos funcionários do museu. As reprovações variavam desde a forma de se vestirem - "não apropriada" - até a higiene pessoal, considerada precária ${ }^{8}$. Com o tempo, padrões de comportamento e formas de vestir consideradas apropriadas para a instituição foram se tornando presentes entre os jovens ${ }^{9}$ e inspiraram comentários: “Hoje fico feliz em vê-los todos arrumadíssimos vindo trabalhar na lojinha. Quando tem coquetel eles vêm todos arrumados, tomam vinho conosco e se comportam super bem". E em outra ocasião, depois de ter reavaliado a questão da bebida alcoólica, o mesmo funcionário comentou:

“Hoje quando eles vêm às vernissages, eles vêm bem arrumados, botam sapato e tudo, e se comportam super bem. Eu inclusive conversei com eles sobre o fato de eles terem que saber se comportar. Não deviam beber porque não caía bem irem conversar com alguém com bafo de bebida. Não cai bem nem para eles nem para ninguém. Eles devem se comportar como qualquer outro funcionário do museu" (grifos meus).

O processo de contenção das pulsões é um fator importante a ser considerado na relação dos jovens com o MAC e o projeto $A_{3}$. A participação de diversas disciplinas no processo de intervenção ${ }^{10}$ e a própria noção de intervenção trazem consigo uma dimensão de civilização dos costumes (Elias 1995) na qual pretende-se uma modificação na sensibilidade e 'refinamento' do comportamento dos jovens que propiciaria o surgimento de novas formas de relacionamentos sociais. A presença de diversas instituições é parte integrante desse processo, sendo estes os agentes sociais que modificam as relações entre os indivíduos ao impor novas formas de convívio. Além do Museu de Arte Contemporânea, a própria transformação do projeto em uma instituição, com a construção de um centro de produção comunitária, atuariam como agentes sociais, complexificando as redes de interdependências e contribuindo para a modificação dos impulsos e emoções.

Dentro dessa concepção de civilização de costumes está implícita a noção de racionalização, que se torna explícita na fala de uma instrutora do projeto: “Eles precisam perceber que não vão ser jovens o resto da vida e que daqui a pouco esses projetos não vão mais aceitar eles" ${ }^{11}$. Surge na fala dessa instrutora a idéia de que esses jovens devessem planejar sua vida, refletindo no presente as conseqüências futuras de seus atos. Está implícita nessa forma de pensar a noção de uma atitude mais racional frente ao mundo e as oportunidades que se apresentam: o mundo como um jogo no qual a compreensão das regras garante o 'sucesso'.

Um bom exemplo da reação dos jovens quanto a essa concepção racional da vida que os profissionais do $\mathrm{A}_{3}$ pretendiam transmitir foi a situação vivida em relação ao ponto de vendas que foi aberto para que eles comercializassem sua produção. O ponto foi concebido pelo coordenador do projeto, que imaginou a oportunidade de vender os produtos produzidos pelas oficinas, gerando uma renda para os jovens e difundindo os artefatos e o projeto para os visitantes do museu. A forma como os jovens o conduziram parece sugerir que a noção de um planejamento da vida em função de um futuro, quando os "projetos não vão mais aceitar eles", é uma concepção que não está em consonância com sua conduta de vida. Investir seu tempo livre na venda dos produtos e abrir mão da praia no sábado de sol, ou do futebol nos domingos, assim como cumprir horários rígidos para abrir e fechar o ponto todos os dias, parece não constituir parte do projeto que esses jovens imaginam para si, ao menos nesse momento de suas vidas. 
Existe, por parte desses jovens, algum nível de assimilação dos discursos de racionalização proferidos pelos quadros do projeto e funcionários do museu. Essa assimilação, entretanto, não parece partir de uma interiorização das noções subjacentes a esses discursos. Essa relação mimética que se apropria da forma, mas não necessariamente do significado, talvez dificulte a percepção, por parte dos profissionais do projeto, dos pontos nos quais o projeto parece fugir às necessidades, desejos e concepções de mundo que fazem parte das representações sociais desses jovens. Na questão do ponto de vendas, por exemplo, é possível perceber essa relação mimética no relato da diretora do museu:

“Logo depois de abrir eles começaram a faltar e, como o (coordenador do projeto) tinha viajado, eu chamei todos para uma reunião. (...) Chamei eles e passei um sermão de 40 minutos. Fui calma, mas dura. Falei muito em compromisso. Disse que se eles não estavam prontos para assumir aquele compromisso, que me trouxessem uma proposta que eu estudaria e decidiríamos juntos o que seria melhor. Ficaram todos de cabeça baixa, um deles (...) só balançava a cabeça afirmativamente o tempo todo. Eu disse que se eles achavam melhor poderíamos montar a loja só nos fins-de-semana. Eles saíram e meia hora depois a (funcionária da divisão de educação) veio dizer que eles queriam falar comigo. Entraram todos e um deles fez a proposta: disse que queriam trabalhar todos os dias e que precisavam de um tempo para fazer o horário. Eu disse para eles que ficava feliz porque achava que eles tinham feito a melhor opção, porque optando por trabalhar a semana toda eles estavam mostrando que estavam dispostos a trabalhar, que aquilo não era só uma brincadeira. Usaram a palavra compromisso o tempo todo, como que respondendo ao meu sermão" (grifos meus).

Oito meses depois o ponto de vendas foi desmontado porque, apesar do discurso dos jovens corroborando a posição da diretora do museu em relação ao compromisso e à responsabilidade assumida por eles, eles continuaram com a mesma relação com o ponto de vendas: compareciam quando lhes era conveniente e freqüentemente chegavam atrasados.

Pode-se questionar também se o comportamento dentro das expectativas dos funcionários do MAC em determinado momento e o não cumprimento das promessas não seriam também formas de acionar situacionalmente valores que foram aprendidos nesse processo. Assim, no momento em que o apreço de um funcionário do museu é mais importante o comportamento condiz com os valores transmitidos pelo projeto, no momento em que é mais importante o futebol ou a praia, valores legítimos entre os jovens, o horário e a promessa de cumpri-lo já não têm tanta importância.

De qualquer forma, a noção de projeto de vida implícita nessa situação relaciona-se a uma percepção temporal que não é uma noção universal, como está claro em estudos como o de Bourdieu com os camponeses da Kabilia (1963). Bourdieu relativiza o conceito de racionalidade econômica a partir da análise do processo de adaptação à economia capitalista pelos camponeses argelinos. $\mathrm{O}$ autor aponta que o sistema econômico sugere um conjunto de atitudes em relação ao mundo e, principalmente, a visão em relação ao tempo, na conduta camponesa em relação à economia. Bourdieu procura entender a mudança social a partir do colonialismo francês que, expondo os camponeses a uma racionalidade econômica capitalista, exigiria uma atitude diferenciada acerca da relação com o tempo e com o futuro. Bourdieu aponta duas formas de percepção temporal: a previdência do camponês (um futuro imediato - avenir) e a previsão (racional) com a idéia de futuro imenso e aberto (um futuro abstrato 
com várias possibilidades). Esses camponeses seriam 'imprevidentes e indiferentes' ao futuro numa visão de mundo capitalista. A noção de futuro para eles estaria baseada no horizonte do presente, na potencialidade atual da consciência da percepção. O avenir seria um futuro imediato, manifestando-se pela apresentação e não pela representação e possuindo uma potencialidade temporal tangível (Bourdieu 1963: 38).

A polidez em relação aos horários seria, para Bourdieu, uma característica empírica das sociedades nas quais a consciência econômica exige uma conduta racional, na tentativa de assegurar a previsibilidade e a calculabilidade. Na pesquisa de campo, foi possível perceber como a racionalização do tempo e a previdência coexistem no interior do mesmo grupo. Ao mesmo tempo que adotavam uma relação ambígua com a proposta do ponto de vendas, os jovens reclamavam constantemente dos atrasos dos instrutores para os compromissos firmados com o grupo. Portanto, se, em determinado nível, o grupo de jovens compartilhava uma consciência temporal própria que não vislumbrava um futuro abstrato no qual diversas possibilidades poderiam existir, em outro, partilhavam com os grupos hegemônicos as noções do racionalismo temporal quando a expectativa da atividade era também deles e não uma construção externa por parte majoritariamente dos profissionais do museu.

O processo de civilização dos costumes implica uma transformação de cima para baixo, um processo de conversão para os padrões da cultura legítima, no qual esta deve fornecer as normas de conduta e de comportamento para que os grupos se modifiquem. A noção de jogo explorada pela oficina neoconcreta lida com a idéia de regras definidas pela arte legítima que servem para conter, restringir a forma de criar e de brincar dos jovens. Esse processo de construção de um discurso organizado que possa ser interiorizado em algum momento pelos jovens está presente no seguinte trecho de conversa durante uma oficina de jogos neoconcretos:

Instrutor: - O que vocês responderiam se perguntassem o que é um jogo?

Rapaz 5: - Todo jogo tem uma regra. Serve para brincar e se divertir, mas tem que seguir a regra. Essa obra tem uma regra (apontando para uma obra de Sérgio Camargo).

Profissional que trabalha no projeto: - Ontem eles falaram que a forma é a regra do jogo.

A forma legítima e a regra que ela institui tornam-se assim o critério a partir do qual o trabalho desses jovens é apreciado, conferindo-Ihes prestígio em uma escala de valores considerados legítimos: a forma (legítima) é a regra do jogo. O que é apreciado não se restringe aos trabalhos artesanais das oficinas, mas se estende ao próprio trabalho de incorporação de novos códigos de conduta que permitam a esses jovens se inserirem na pequena política do dia-a-dia, aquela que discorre sobre as regras de reputação, sobre como jogar o jogo social. Bailey (1971) mostra como todos nós vivemos essa pequena política, de alguma forma, em nosso cotidiano. Participar do jogo social implica distinguir o que está em jogo em cada papel social desempenhado pelos indivíduos. O desempenho dos papéis implica por sua vez o reconhecimento de uma comunidade de valores e categorias compartilhadas pelo grupo. Os sinais que comunicam o desempenho desses papéis podem ser de fala ou de gestos e servem para desencadear o julgamento da situação configurada. A partir desses julgamentos as reputações são construídas e destruídas. 
O que esses jovens mostraram ao longo da observação etnográfica é que o reconhecimento dos valores do grupo de profissionais do museu e a mimese dos discursos por parte dos jovens não necessariamente significa uma mudança em seus próprios valores. O processo parecia ter sido compreendido, entretanto, as noções acionadas pela oficina pareciam estar relacionadas à experiência diretamente vivida, mas não constituírem um valor para eles. Portanto não era suficiente para compreender a reação dos jovens frente aos conceitos transmitidos pelo projeto $\mathrm{A}_{3}$ considerar a capacidade desses jovens de entender, reproduzir e mesmo produzir discursos sobre arte, responsabilidade, compromisso etc.

\section{LINGUAGEM E IDENTIDADE ${ }^{12}$}

A língua, durante as discussões a respeito da constituição dos Estados-nação, foi tida como um dos elementos que, demarcando a identidade étnica ou nacional de um grupo, se pressupunha homogênea, portanto passível de ser estudada como encerrando um significado em si. Definidas essas instâncias políticas, pôde-se voltar a discussão em direção às línguas em sua relação com a identidade dos grupos no interior de um mesmo Estado: as línguas passaram a ser consideradas, então, imersas em suas condições sociais de produção e de utilização. Essa nova abordagem permitiu perceber como a ubiqüidade e a polissemia do código lingüístico ocasionam interpretações equivocadas a respeito de uma pretensa unidade interpretativa entre diferentes classes (sociais, de gênero, de geração, assim como de profissões que portam terminologias e formas lingüísticas específicas em cada área de atuação).

Assim como a linguagem verbal, a decodificação da linguagem visual está relacionada à singularidade da experiência, constituindo-se em uma "relação socialmente caracterizada na qual os receptores empregam a diversidade de seus instrumentos de apropriação simbólica" (Bourdieu 1996: 25). As linguagens acionam metáforas relacionadas às representações do mundo social por elas veiculadas. Apesar de serem meios comuns, a comunicação, tanto verbal, como visual, não têm existência em si, mas apenas quando imersas em situações.

Partindo do pressuposto de que existe uma economia dos bens culturais, Bourdieu procura compreender as "condições nas quais os produtores desses bens, assim como seus gostos por eles, são produzidos, ao mesmo tempo que descrever as diferentes formas de apropriação desses objetos que em momentos particulares são designados como objetos de arte, e as condições sociais de constituição do modo de apropriação que é considerado legítimo" (1998:1). Para o autor, todas as práticas sociais, desde as visitas a museus até as preferências literárias e musicais, estariam intimamente relacionadas ao nível educacional e à origem social, o que instituiria uma hierarquia social de consumidores correspondente à hierarquia das artes socialmente reconhecidas e, dentro de cada uma delas, uma hierarquia de gêneros, escolas, períodos etc. Para Bourdieu, de todos os objetos oferecidos para a escolha do consumidor, as obras de arte legítimas seriam as mais classificadoras, sendo elas mesmas dividas e sub-divididas ad infinitum. Esse sistema de classificação hierárquica predisporia o gosto a ser tomado como um critério de aferição, ou um rótulo de classe social que, no entanto, seria dissimulado por uma ideologia que naturalizaria o gosto na 
cultura legítima como um dom da natureza, obliterando o caráter culturalmente construído no qual a educação tem papel privilegiado, contribuindo para converter as diferenças no modo de aquisição em diferenças naturais.

Sendo um instrumento de ação sobre o mundo social, a linguagem aciona relações de força entre os locutores e os receptores. A hierarquização dessa relação e a imposição de uma linguagem estranha ao ambiente social das pessoas pode ocasionar o mutismo daqueles a quem se reserva uma posição subordinada, isto é, de incompetência técnica e social de expressão. A desconsideração das disposições específicas que implicam uma propensão a falar determinadas coisas acaba impondo certas sanções e censuras que contribuem para o tolhimento da expressão. A própria forma do museu pode ilustrar o mutismo, nesse caso expresso pela insegurança que pode se impor ao se adotar uma linguagem que não faz parte do mundo social daqueles com quem se pretende trabalhar. A linguagem arquitetônica de Niemeyer, enaltecida por alguns grupos como moderna e inovadora, surgiu como um empecilho para a ida da mãe de um dos jovens ao museu, que tinha medo por achar que "o museu vai cair".

Esse mutismo não passa necessariamente pelo silêncio, ele pode manifestar-se, também, na forma ambígua da adoção de um comportamento mimético. Na produção artística dos jovens esse mimetismo pode estar relacionado à compreensão de uma linguagem que satisfizesse aos instrutores, ao invés do desenvolvimento de uma forma de expressão própria através da linguagem visual. Em uma conversa entre o instrutor de jogos e os jovens, ficou explícita a preocupação em trabalhar dentro dos cânones legítimos:

Instrutor: - Nós estamos fazendo com que vocês falem coisas em frente às obras de arte que vocês nunca falaram antes.

Rapaz 2: - Tamos ficando maluco.

Instrutor: - Olha, isso aqui é maluquice, - apontando para um trabalho que, reproduzindo a forma/regra da obra de Sérgio Camargo, formava um jogo de peças de sabão bastante parecido com a própria obra de Camargo - o negócio é que isso gera museu.

O fato de estar vinculado a uma instituição museal e a um movimento artístico específico parece dificultar a inclusão de noções que não estejam diretamente relacionadas ao movimento em questão, sem que haja qualquer explicação sobre a legitimidade de alguns objetos de arte e não de outros. Assim, as idéias de precisão do traço, retas e curvas perfeitas - noções enfatizadas na oficina - teriam sido questionadas por um dos jovens, "mas poderia não ser precisa e ainda assim ser bonita", sem que sua argumentação fosse ouvida, ou se o foi, não fosse levada em conta. Jovem extremamente articulado e sensível, não seria forçar uma interpretação imaginar que seu argumento estivesse referido à 'organização arquitetônica' do Morro do Palácio.

Observando a arquitetura do espaço social do Morro do Palácio, é tentador relacionar a contestação do rapaz ao seu ambiente social. A noção de esquadro, de precisão de linhas, de geometria que implica a idéia de racionalidade poderia ser compreendida como um critério de beleza subjacente a espaços de urbanização divididos em norte, sul, leste, oeste, trabalhando com paralelas, perpendiculares, curvas e contra curvas. A 'geometria' do 'morro' é 'sensível', as formas não são feitas com instrumentos de precisão, mas se desenvolvem de maneira integrada às possibilidades e necessidades das pessoas e dos espaços físicos que, não estando subordinados a demarcações institucionais, são reguladas pelas relações de vizinhança. Essa 'geometria' está menos preocupada 
com a precisão e a rigidez das normas de arquitetura e geometria, parecendo levar em consideração, principalmente, as relações interpessoais, as necessidades e as possibilidades restritas de espaço e econômicas. O espaço físico torna-se quase um objeto de 'experimentação arquitetônica' que pode parecer, e em geral parece, aos habitantes das áreas de arquitetura racional, tão estranho quanto o prédio do MAC para os moradores do Morro do Palácio.

Essa questão ilustra a dificuldade em trabalhar com a percepção dos jovens e adaptá-la à linguagem dos jogos produzidos através das obras de arte. $\mathrm{O}$ caminho acaba sendo trabalhar com as noções subjacentes às obras para que eles produzam os jogos - pequenas obras móveis - dentro de uma linguagem definida pelo artista e legitimada pelo museu, sem criarem eles mesmos sua linguagem. Nesse sentido, a precisão poderia ser percebida como uma linguagem que exclui, já que o mundo desses jovens não é preciso. A proposta da oficina acabava estando voltada mais para um processo de industrialização, preocupado com a venda dos artefatos que, produzidos por um projeto social do Museu de Arte Contemporânea de Niterói, precisavam seguir padrões estéticos definidos por esta instituição, do que um processo que traduzisse as percepções de mundo dos jovens em uma linguagem visual própria. A 'sensibilização' se dava para a linguagem legítima e não necessariamente para o desenvolvimento de novas linguagens.

Na dimensão verbal da linguagem, a utilização corriqueira de palavras que os jovens tinham dificuldade em compreender colocava o falante, no caso o instrutor, como o detentor da legitimidade contra a qual os jovens só tinham o que aprender. Ao menos em duas situações específicas os jovens demonstraram não compreender o discurso de profissionais do projeto: em uma das situações um deles me perguntou discretamente o significado da palavra extrovertido e, em outra, o grupo demonstrou certo constrangimento ao não compreender uma pergunta que usava o termo insight. Isso inclui a questão acima exposta da linguagem visual e ainda a questão da "maluquice" como "geradora" de museus, como apresentado pelo instrutor no trecho de diálogo acima reproduzido. O desconhecimento dos processos sociais que levam ao reconhecimento de Sérgio Camargo, por exemplo, como artista plástico, e de suas obras como passíveis de serem expostas em um museu, mas não de qualquer obra produzida com as mesmas regras, torna os profissionais ligados ao mundo das artes plásticas detentores de um poder de consagração que é constantemente enfatizado em falas e atitudes.

Não está excluído desse jogo o reconhecimento, por parte dos jovens, da legitimidade dos profissionais do museu explícita na declaração dos jovens quanto à expectativa de elogios por parte daqueles. Entretanto, o reconhecimento da legitimidade supõe o reconhecimento de sua própria incompetência em expressar-se já que não possuem o domínio dos códigos legítimos. Segundo Bourdieu (1996b), ao mesmo tempo que os princípios do jogo são dissimulados, o jogo é produzido e reproduzido pelos que se encontram nele envolvidos. A adesão ao jogo implica reconhecer o valor do jogo que define o reconhecimento da legitimidade.

A proposta da oficina de jogos neoconcretos consistia na descoberta de critérios que configurariam a regra a ser seguida. O desafio era produzir, a partir dessa regra, um objeto que se daria a perceber/conhecer como um jogo de formas, cores, texturas, intenções, cujas possibilidades interpretativas diversas poderiam fazer surgir no olhar do observador critérios ainda outros capazes de produzir novas regras a partir das quais o jogo poderia ser 
fruído. A idéia de jogo social pode ser interpretada a partir de parâmetros parecidos: descobertas as regras da conduta social, o desafio estaria em conciliar as possibilidades sociais e as individuais para a obtenção de resultados social e individualmente satisfatórios. Entretanto, os instrumentos mínimos para o reconhecimento das estratégias e regras intrínsecas ao mundo artístico não são formulados. Assim, ao serem convidados a participar de um evento que não trazia associado o nome do MAC, a experiência de terem seus trabalhos não reconhecidos como estavam acostumados sempre que o nome do museu e dos artistas que participam daquele mundo estavam vinculados ao projeto $A_{3}$, a reação dos jovens foi de raiva e incompreensão.

\section{À GUISA DE ENCERRAMENTO}

A construção da identidade social do grupo de jovens ocorreu no interior de uma série de relações na qual vários jogos se desenvolveram, contribuindo para a constante modificação das próprias relações nas quais esses jogos se desenrolaram. A ampliação da rede de interdependências e a conseqüente modificação nos relacionamentos sociais através das novas relações que o projeto Arte em Ação Ambiental colocou em jogo, através de diferentes linguagens e escalas de valores, pôde ser observada durante o trabalho de campo.

O grupo de jovens que passou a freqüentar o projeto $A_{3}{ }^{13}$ passou também a participar direta ou indiretamente de diferentes dimensões nas quais diversos jogos sociais se desenrolavam e, conseqüentemente, influenciavam na construção de sua identidade social: a classificação da coleção Sattamini ${ }^{14}$ como um jogo entre os agentes e agências do campo artístico para tornar diferenciada a participação de um museu de periferia no campo de instituições do gênero no Estado; a escolha do arquiteto Oscar Niemeyer, cuja representação social aciona imagens de filantropia e preocupação social, colocando em evidência uma política municipal que se pretendeu voltada para a cultura; a opção da Divisão de Educação por acionar um programa educativo que pretendia trabalhar a identidade social de um grupo de jovens economicamente desfavorecidos através da arte; a opção desse projeto por uma vinculação ao museu em oposição à adoção de uma identidade relativamente independente de organização não-governamental; a morosidade do Estado na concessão de financiamento para o projeto, contrapondo-se à persistência dos instrutores em trabalhar com o grupo de jovens; e a construção de afetos de ambas as partes, dos instrutores em relação aos jovens e dos jovens em relação aos instrutores.

Huizinga (1993: 33) compreende a noção de jogo como “uma atividade ou ocupação voluntária, exercida dentro de certos e determinados limites de tempo e de espaço, segundo regras livremente concedidas, mas absolutamente obrigatórias, dotado de um fim em si mesmo, acompanhado de um sentimento de tensão e de alegria e de uma consciência de ser diferente da 'vida cotidiana'". Ao contrário da noção de jogo que esse autor apresenta, o jogo social que se apresentou à observação em campo não possui regras rígidas, mas estratégias que estiveram referidas aos diversos valores e às formas de relacionamento no interior dos campos nos quais se inseriam os agentes que participaram dos jogos. Na noção de jogo social não há a separação espaço-temporal do ambiente cotidiano, havendo sempre algum tipo de prazer/finalidade reconhecido, mas não necessariamente conhecido. 
A arte e as relações que estiveram em jogo nesses jogos de força, cujos valores considerados são subjetivos, serviram como instrumento na construção da identidade social do grupo de jovens através das diversas noções ${ }^{15}$ que fizeram parte desse processo: trabalho, distinção, prestígio, responsabilidade, criatividade, arte etc. Entretanto, o processo de construção de identidade não se deu, exclusivamente, na aprendizagem e na experimentação artística mas, principalmente, no processo de estabelecimento das relações sociais. As artes surgiram, então, como o fio condutor através do qual essas relações puderam se estabelecer, sendo que o prestígio instituído pela participação em uma instituição de prestígio como o MAC conferiu ao projeto $A_{3}$ uma dinâmica que lhe foi, às vezes, aliada, às vezes, inimiga.

Pensando a questão do poder implícita no processo de comunicação, Bailey (1971) refere-se à reciprocidade como uma competição que só ocorreria entre pessoas de mesmo status competindo pelo mesmo prêmio ${ }^{16}$. Uma diferença muito grande em termos de status colocaria as pessoas em posições tão distantes que a competição entre elas seria impraticável, mas não a possibilidade de uma usar a outra para determinados fins. Appadurai (1986), por sua vez, cunhou a noção de torneio de valores para pensar as diversas arenas inter-relacionadas nas quais vários tipos de trocas de conveniências são efetuadas tendo o ganho em uma implicações para as outras. Esses torneios seriam eventos periódicos complexos removidos da rotina da vida econômica. Essa noção é próxima à definição na qual Baudrillard (citado por Appadurai 1986: 21), inclui as festas e os jogos. Para o autor, a participação nesses torneios é ao mesmo tempo um privilégio daqueles que têm poder e um instrumento de disputa de status entre eles. O que estaria em questão nesses torneios seria principalmente status, fama, posição e reputação dos atores. $\mathrm{Na}$ citação de Baudrillard este autor argumentou a respeito da base de paridade (que não teria nada a ver com a igualdade da competição econômica), isto é, os valores e privilégios que os indivíduos deveriam compartilhar para disputar, ou jogar.

A partir das observações da implementação e desenvolvimento do projeto $A_{3}$ foi possível percebê-lo como um sistema de trocas no qual há um incremento de reputação, nome e fama para algumas pessoas e o capital para produzir esse 'lucro' são outras pessoas, os jovens que participam do projeto. Usando Appadurai e Bailey e a questão da paridade, ou igualdade de status, os jogos que se travaram no interior de todo o processo de implementação e desenvolvimento do projeto Arte em Ação Ambiental foram travados no interior de cada grupo de status e não entre os diversos grupos de status envolvidos, isto é, entre os diversos jovens, entre os profissionais do projeto, entre os diversos personagens políticos envolvidos no processo de liberação de recursos, mas não entre indivíduos de cada um desses grupos. Assim, a descoberta das regras legítimas por parte do grupo de jovens não significava necessariamente a participação no jogo do grupo hegemônico, ou o ingresso no mundo artístico (Becker 1982).

Há, entretanto, uma dimensão na qual os jovens do Morro do Palácio controlam o fluxo de profissionais que participa do projeto. A oficina de programação visual ${ }^{17}$, por exemplo, não teve muitos participantes, em certa medida por não estar diretamente vinculada ao projeto e, portanto, não atribuir àqueles que dela participavam uma posição de prestígio dentro do museu e da sua própria comunidade. Entretanto, uma vez tendo re-entrado no projeto como pesquisadora, o reconhecimento do trabalho como objeto de uma pesquisa acadêmica foi percebido 
como legitimador do projeto e da própria comunidade da qual os jovens se percebiam como pertencentes e, portanto, as 'portas foram abertas' para uma relação mais próxima entre os jovens e a pesquisadora e também para a participação desta em eventos no morro que não estivessem vinculados ao projeto $A_{3}$. Existia também uma reclamação dos profissionais do projeto quanto à não divulgação dos jovens sobre o projeto junto a outros jovens do Morro do Palácio, isto é, havia por parte dos participantes um controle de quais pessoas deveriam partilhar do privilégio de participar do projeto. Assim, por mais que o jogo entre grupos sociais distintos esteja sempre permeado por conjuntos de valores hegemônicos, os grupos sociais com menos poder social não estão isentos de formas de controle. É importante admitir a desigualdade de poder nas relações entre grupos distintos, mas também é importante atribuir aos grupos minoritários (Wallerstein 1991) autonomia em algumas esferas nas quais esses grupos utilizam as representações a eles atribuídas de forma instrumental. 
1 Este artigo é resultado das reflexões desenvolvidas no âmbito da dissertação de mestrado "'A Forma é a Regra do Jogo'. Educação estética e construção de identidades entre um museu de arte e um grupo de classe popular", defendida em 2002.

2 A noção de educação não-formal refere-se ao ensino em museus, espaços culturais, organizações não-governamentais, associações, igrejas etc. Essa noção surge como uma tentativa de abranger os processos educativos não considerados formais por não ocorrerem nas escolas, mas que tampouco podem ser classificados como informais já que dispõem de estruturas que organizam os processos de ensino-aprendizagem (Gohn 1998).

3 Informal por não fazer parte oficial do projeto $A_{3}$, não ter horário definido, acontecendo esporadicamente dentro dos horários disponíveis, tendo sido iniciada dois meses depois do início do projeto e terminado antes do fim deste.

4 A designação "jovem" é o termo nativo adotado para referir-se aos participantes do projeto que deveriam residir no Morro do Palácio, localidade próxima ao MAC e alvo de outros projetos municipais, principalmente após a inauguração do museu. Há um sentido político/comercial atribuído ao rótulo que classifica as pessoas autorizadas a participar, o público-alvo dos projetos. O termo foi acionado como categoria no discurso de todos os envolvidos com a implementação desse e de outros projetos de intervenção que atuavam na área ou que estavam de alguma forma relacionados ao $\mathrm{A}_{3}$. "Jovem", portanto, é parte constitutiva da identidade coletiva desses grupos, participando de uma hierarquia social que define um lugar na estrutura das relações de poder da malha social. Considerando que as posições são sempre relativas e devem ser consideradas à luz das outras posições na estrutura social, podemos perceber como essa classificação foi utilizada para denotar um determinado privilégio em relação a outras categorias (como crianças, idosos, adultos etc) excluídas de participar dos projetos oferecidos. Portanto a construção da identidade começa na própria definição do público-alvo. A faixa etária dos participantes do projeto é bastante ampla, indo de 12 a 21 anos. Ciente de que esta é uma categoria socialmente construída, mas também uma realidade naturalizada através de diversos mecanismos sociais, foi uma opção abrir mão das aspas ao usar tal categoria.

5 As citações inseridas neste tópico referem-se às diversas versões documentais do projeto Arte em Ação Ambiental.

6 O Neoconcretismo foi um estilo artístico carioca que fez parte do movimento construtivo que caracterizou a arte carioca e paulista na década de 50

7 Apesar de o período de observação participante ter sido de menos de um ano, o fato de já ter estagiado no MAC quando o $A_{3}$ estava começando e de ter participado de uma oficina ministrada depois que o projeto já estava em andamento há algum tempo permitiu um parâmetro de comparação para algumas transformações observadas entre os jovens. O tempo total de observação desde o estágio até a escritura da dissertação foi de mais ou menos três anos durante os quais a observação e a participação constituíramse de intensidades diferenciadas.

8 Os shorts e blusas minúsculas das moças constituíam o principal alvo das reclamações, mas as bermudas e chinelos de dedo de borracha dos meninos também eram motivo de incômodo. Com relação à higiene, reclamava-se da falta de uso de desodorantes.

9 Bourdieu (1987) analisa o sentimento de estar excluído da cultura legítima como a expressão mais sutil da dependência, implicando a impossibilidade de excluir o que exclui e apresentando a adoção das normas legítimas de conduta como um dos pólos contraditórios entre uma resistência alienante e uma submissão que poderia ser libertadora. Entretanto, como veremos adiante, parece existir uma terceira possibilidade que considera a relação mimética como uma forma de se relacionar com os padrões de conduta considerados legítimos sem, contudo, abandonar completamente as normas de comportamento anteriores à intervenção.

10 Vários agentes representantes de diferentes áreas de saber estiveram envolvidos, de alguma forma, no $\mathrm{A}_{3}$ : medicina (Programa Médico de Família), educação (Secretaria de Educação), economia (BNDES, Petrobrás etc.), comunicação (Projeto BemTV, departamento de comunicação da UFF).

11 Ver nota 4

12 Centrou-se a análise sobre as linguagens nas observações realizadas na oficina de jogos neoconcretos, devido a sua vinculação mais direta ao MAC e por ser esta um dos principais eixos do projeto de intervenção. 
13 Para aprofundar essas outras dimensões da pesquisa ver Reinheimer (2002 e 2003).

14 Coleção particular que foi oferecida, em comodato, ao MAC.

15 Esse termo, noção, foi utilizado durante algum tempo como uma gíria pelos jovens. "Noção" parecia ter, então, um significado amplo relacionado a tudo que deveria ser compreendido, interiorizado, durante o trabalho com os profissionais do projeto. Era proferida como uma interjeição, solta, sem qualquer complemento: "Noção!". Após algum tempo ela foi completamente abandonada.

16 Um dos rapazes que participou do projeto desde o início falou sobre seu descontentamento com a forma como foi tratado pelo grupo. O rapaz destacou-se por seu domínio da expressão verbal e das noções que estavam sendo transmitidas pelo projeto, o que the reservou uma posição privilegiada no interior do grupo, atribuída pelos próprios jovens e pelos instrutores do projeto. Em novembro de 1999, houve um seminário sobre museus e sua relação com as "comunidades", na Bahia. O MAC se disponibilizou a financiar para que um dos jovens do projeto fosse ao seminário. Houve uma votação entre os jovens e esse rapaz foi o escolhido. Após a confirmação de seu prestígio, o rapaz passou a ser alvo de implicâncias por parte dos outros participantes: "Eles ficavam me zoando, quando eu fui escolhido para ir para a Bahia para aquele seminário. Todos ficaram pegando no meu pé". O rapaz acabou saindo do projeto.

17 Antes de iniciar o mestrado eu havia oferecido uma oficina de introdução à programação visual para os jovens integrantes do projeto $A_{3}$. 


\section{REFERÊNCIAS BIBLIOGRÁFICAS}

APPADURAI, Arjun. 1986. "Introduction". In A. Appadurai (ed.) The Social Life of Things: Commodities in cultural perspective. New York: Cambridge University Press.

BAILEY, F. G. 1971. “Gifts and Poison”. In Gifts and Poison: The politics of reputation. Oxford: Basil Blackwell.

BECKER, Howard. 1982. Art Worlds. Los Angeles: University of California Press.

BOURDIEU, Pierre. 1963. "La Société Traditionelle. Attitude à l'égard du temps et conduite économique". Sociologie du Travail: 24-44.

. 1987. “O Mercado dos Bens Simbólicos". In A Economia das Trocas Simbólicas. São Paulo: Perspectiva.

1996. “O Mercado dos Bens Simbólicos”. In As Regras da Arte. Gênese e estrutura do campo literário. São Paulo: Companhia das Letras.

. 1996b. A Economia das Trocas Linguísticas. São Paulo: Edusp.

1998 [1979]. Bourdieu, Pierre. Distinction. A social critique of the judgment of taste. Cambridge: Harvard University

Press.

DUNCAN. Carol. 1995. Civilizing Rituals: Inside public art museums. London: Routledge.

ELIAS, Norbert. 1995. O Processo Civilizador. Volumes I e II. Rio de Janeiro: Jorge Zahar.

GOHN, Maria da Glória. 1998. "Educação Não Formal: Um novo campo de atuação". Ensaio: avaliação e políticas públicas de educação 6(21): 511-26. Rio de Janeiro.

HUIZINGA, Johan. 1993. Homo Ludens. São Paulo: Perspectiva.

REINHEIMER, Patrícia. 2002. "A Forma é a Regra do Jogo". Educação estética e construção de identidades entre um museu de arte e um grupo de classe popular. Dissertação de mestrado. Rio de Janeiro: UFRJ, Museu Nacional, Programa de Pós-Graduação em Antropologia Social.

. 2003. "Construção de Identidade: A relação entre o Museu de Arte Contemporânea e o município de Niterói". Cadernos de Antropologia e Imagem 16(1): 65-74.

WALLERSTEIN, Immanuel. 1991. The Construction of Peoplehood: Racism, nationalism, ethnicity. In Race, Nation, Class. Ambiguous Identities. Londres: Verso. 


\section{Arte e Identidade: Estratégias do jogo social}

\section{RESUMO}

O ensaio procura refletir sobre as estratégias dos diferentes atores sociais envolvidos em um projeto de intervenção inscrito dentro de uma instituição de conservação cultural com uma posição relativamente privilegiada dentro do campo artístico. A noção de jogo, categoria nativa do projeto investigado, é usada, a partir das observações de campo, para refletir sobre o processo de construção da identidade social de um grupo de jovens de classes economicamente desprivilegiadas que são o público-alvo desse projeto no qual a produção artística, apesar de ser apenas um dos elementos considerados, é justamente aquele que permitiu colocar em jogo as relações conflituosas entre os diferentes interesses expressos nos jogos sociais acionados para construir, manter e destruir reputações.

PALAVRAS-CHAVE: jogo; arte; identidade; intervenção social.

\section{Art and Identity: Strategies in a social game}

\section{ABSTRACT}

This article focuses the strategies of different social actors involved in an intervention project developed by a cultural conservation institution with a relatively privileged position in the artistic field - the Museu de Arte Contemporânea of Niteroi (Rio de Janeiro, Brazil). The notion of game is a native category used by the social actors involved in the investigated project. This notion is taken from the field observations to analyze the process of social identities' construction within a group of economically underprivileged young people which are the target of this project. The artistic production, although not the sole element considered, allowed the conflictive games between different interests to express themselves in the social games set in motion in the construction, keeping and destruction of reputations in that context.

KEY WORDS: game; art; identity; social intervention.

Recebido em 09/02/2006

Aprovado em 29/05/2006 